\title{
Microbiology and Evolutionary Advances of Different Types of Pathogens in Human and Biological Conservation
}

Muhammad Tahir ${ }^{1}$, Ahmed Aniq Raza ${ }^{2}$, Hira Iqbal ${ }^{3}$, Faiza Marrium ${ }^{4}$, Ghazanfar Hameed ${ }^{5 *}$, Muhammad Iqbal ${ }^{6}$, Faryal Manzoor $^{7}$, Warda Yasmeen ${ }^{8}$

${ }^{1}$ Department of Epidemiology \& Public Health, University of Agriculture Faisalabad, Pakistan

${ }^{2}$ Institute of Microbiology University of Agriculture Faisalabad, Pakistan

${ }^{3}$ Nutrition Division, National Institute of Health, Islamabad 44000, Pakistan

${ }^{4}$ Tetanus Toxoid Production Lab, Biological Production Division, National Institute of Health, Islamabad 44000, Pakistan

${ }^{5}$ Department of Zoology, Ghazi University, Dera Ghazi Khan, Pakistan

${ }^{6}$ Department of Biological Science, Government Girls Degree College, Skardu

${ }^{7}$ Department of Life Sciences (Biochemistry), University of Management and Technology (UMT), Lahore, Pakistan

${ }^{8}$ Department of Zoology, Government College University Faisalabad, Pakistan

DOI: $10.36348 /$ sjpm.2022.v07i01.004

| Received: 09.12.2021 | Accepted: 18.01.2022 | Published: 24.01.2022

*Corresponding author: Ghazanfar Hameed

Department of Zoology, Ghazi University, Dera Ghazi Khan, Pakistan

\section{Abstract}

Different factors involved in increasing the risk of infectious diseases caused by genetic and environmental changes. Due to high risk of infectious diseases such as chronic kidney disease, osteoarthritis, osteoporosis, Alzheimer's disease, cataracts, advances have been made in the fields of molecular sciences and engineering technology for highly effective tools and high-throughput omics technologies. Ebola virus is the most contagious as compared to the other viruses colds, influenza, or measles. Pathogenic bacteria are involved in causing of infectious diseases. Hib disease is the serious public health concern disease caused by Haemophilus influenza. Norwalk virus also causes serious abnormalities in the digestive system that ultimately leads to muscle cramp. Antimicrobial resistance have been challenging in the fields of biomedical sciences. Sequencing of bacterial genomes helpful for track the different status of fates of mutations that rise and fall through indication of multiple replicates. Genetic engineering based biomedical therapies needed to understand the target microbial cell, protein factory that secreted the variety of products.

Keywords: Antimicrobial resistance, biomedical sciences, bacterial genomes, infectious diseases.

Copyright ( 2022 The Author(s): This is an open-access article distributed under the terms of the Creative Commons Attribution 4.0 International License (CC BY-NC 4.0) which permits unrestricted use, distribution, and reproduction in any medium for non-commercial use provided the original author and source are credited.

\section{INTRODUCTION}

Infectious diseases are the major cause of deaths arises due to the infections caused by pathogenic microbes [1, 2]. There is increase in the resistance developed against different types of antibiotics that have been used for targeting microbes and infectious particles. But, there is sufficient knowledge of molecular of different genes causing risk of multiple diseases. Due to high risk of infectious diseases, these can be divided into communicable, which are caused by pathogens and increased the risk of transferring it from one person to another, or from one organism to another. The most important communicable diseases include measles, food poisoning and malaria. While on the other hand, non-communicable, which have low or no risk of transferring it from one person to another, or from one organism to another included the chronic kidney disease, osteoarthritis, osteoporosis, Alzheimer's disease, cataracts [3-4]. Advanced technologies in the fields of molecular sciences and engendering technology has leads down the foundation of instruments designing of new and highly effective tools and high-throughput omics technologies have been used use for the next generation of tools, which open new windows into the molecular makeup of an individual [5, $6]$. 


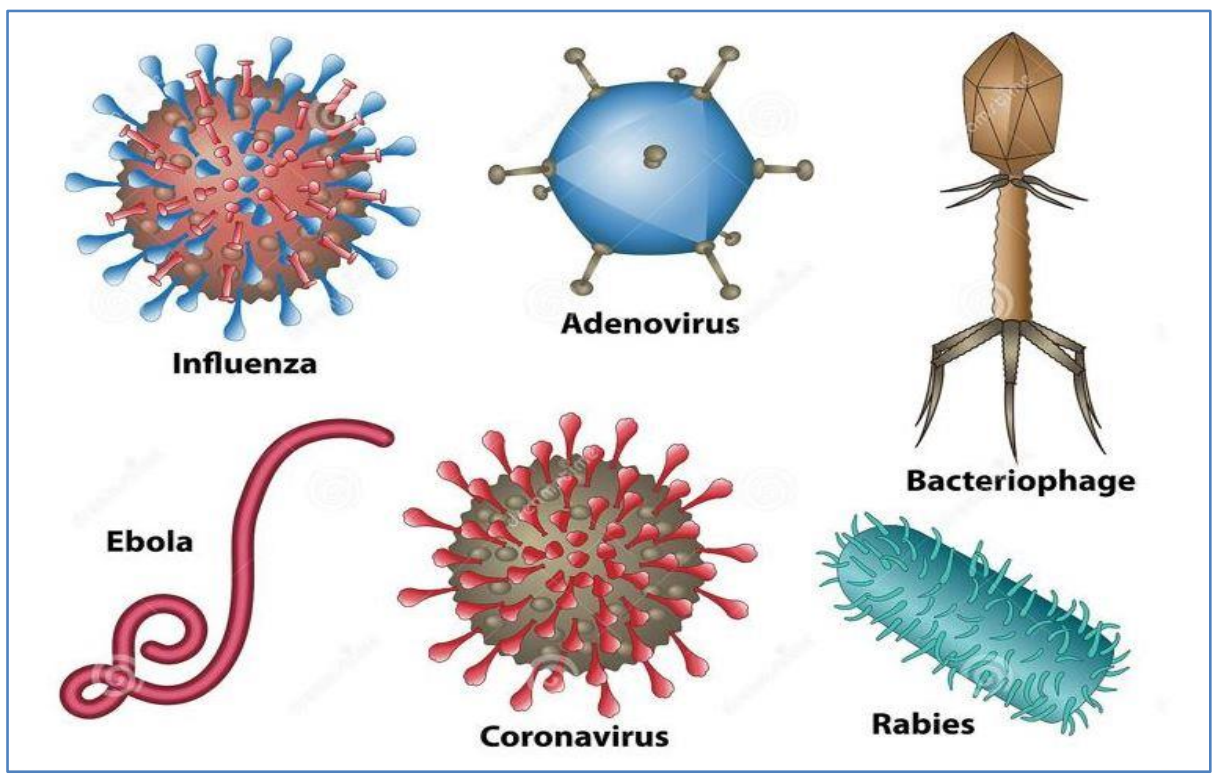

Fig-1: Shows the clinical risk of major infectious diseases

\section{Microbiology and evolutionary advances pathogens and biological conservation}

Ebola virus is the most contagious as compared to the other virus's colds, influenza, or measles. This virus can transmit from person to person, and special feature of this virus is affecting a large number of people while on the other hand, other viruses have low prevalence rate and affecting a small number of people. Different medications have been used as therapeutics such as monoclonal antibodies such as Inmazeb and Ebanga were approved for the treatment. Inmazeb targets and binds to the glycoprotein that on the surface of Ebola virus. The survival rate has improved greatly as new antibody treatments offer hope for survival rates to continue to improve. But there is need to further investigate the roles of this virus in targeting the immune cells and cellular responses as result of confections $[1,5,6,9]$.

Hib disease is the serious public health concern disease caused by Haemophilus influenza. That affected both individuals such as common in childrens and adults. While on the other hand, risk increasing in those people taking medical chemotherapy or medicines for cancer. The immune system elects the response poorly and causes disability that progressed to the normal cells. Hib disease may be transmitted through contact with mucus or droplets from the nose and throat of an infected person. To diagnose Hib disease, a small sample of blood, spinal fluid, or another body fluid for testing and antibiotics might be used in orlder to control the growth of bacteria that causes malfunctioning and thus decreases the severity of the disease at early stage of infection with right of diagnosis [7-9].
Norwalk virus is the type of infectious viruses that causes serious abnormalities in the digestive system such as diarrhea which ultimately leads to muscle cramp due to unbalance of nutritional balance [10-12]. It can be transmitted to the healthy person from infected one that depends upon on the immunity and comprised systems under medications or chemotherapy under treatment of cancer. It is the leading cause of food poisoning occurring at the high rate and needed preventive measures. The other symptoms included the severe headache that causes pain to all body parts. Some of the chemical and molecular analysis of stool with no inflammatory cells and culture is negative for bacteria known to cause infectious diarrhea [25, 26]. Pathogenic microbes are major cause of increasing the number of multiple diseases especially those associated with cardiovascular system [27-29].

Different factors involved that increased the risk of infectious diseases are genetic and environmental. The most forms are cancer and cardiovascular that has been a major problem in the public health sectors. Molecular and cellular biology with advances in controlling the attack of infections microbes made significant revolution. Many of the pathogenic microorganisms that enter our body and cause the disease are termed as an immediate cause for illness and sometimes conditions becomes serious for leading to the root of cancer [3-4]. Sigma factors are protein subunits of bacterial RNA polymerases (the enzymes that synthesize RNA from a DNA template), and control the initiation of transcription at the promoter sequence (unique sequences that define the start of a gene) [5-6]. 
Muhammad Tahir et al; Saudi J Pathol Microbiol, Jan, 2022; 7(1): 24-28

Table-1: Shows the different factors for causing, significance of infectious diseases

\begin{tabular}{|l|l|l|l|}
\hline Infectious Risk Factor & Cause Agent & Implications & Significance \\
\hline Infectious diseases & $\begin{array}{l}\text { Genetic and } \\
\text { environmental. }\end{array}$ & High risk of infectious diseases & Osteoporosis, Alzheimer's disease \\
\hline Ebola virus & $\begin{array}{l}\text { Viral } \\
\text { infections }\end{array}$ & $\begin{array}{l}\text { The most contagious as } \\
\text { compared to the other virus's } \\
\text { colds, influenza, or measles. This } \\
\text { virus can transmitted from person } \\
\text { to person, and special features }\end{array}$ & $\begin{array}{l}\text { The survival rate has improved } \\
\text { greatly as new antibody treatments } \\
\text { offer hope for survival rates to } \\
\text { continue to improve. }\end{array}$ \\
\hline Hib disease & $\begin{array}{l}\text { Can be transmitted through } \\
\text { contact with mucus or droplets } \\
\text { from the nose and throat of an } \\
\text { infected person }\end{array}$ & $\begin{array}{l}\text { Antibiotics might be used in order to } \\
\text { control the growth of bacteria that } \\
\text { causes malfunctioning and thus } \\
\text { decreases the severity of the disease } \\
\text { at early stage of infection with right } \\
\text { of diagnosis }\end{array}$ \\
\hline Norwalk virus & $\begin{array}{l}\text { Microbial } \\
\text { infection }\end{array}$ & $\begin{array}{l}\text { Ultimately leads to muscle cramp } \\
\text { due to unbalance of nutritional } \\
\text { balance. } \\
\text { of increasing the number of multiple } \\
\text { diseases especially those associated } \\
\text { with cardiovascular system }\end{array}$ \\
\hline
\end{tabular}

Sigma factors are involved in bacterial assembly of protein and there is less data available for targeting the different gens involved in overall signal processes. Although, sigma factors are a major regulator of prokaryotic gene expression following the sequential mechanism of promoters [23, 29]. Combinations of antibiotics have been used in few past years but resistance to some of chemical drugs made challenges for discovery of novel compounds on the basis of genes causes mutational changes of bacteria to the living body. It depends upon on the growth of specific antibiotic used for the particular pathogens. Very low concentrations affected the gene structure of bacteria and protein assembly but bacteria can develop resisted due to changing environment. Optimum concentrations disintegrated the gene structure of bacteria and protein assembly and in most of cases; bacteria cannot develop resisted due to the insufficient environment. Whole genomic sequencing of bacteria is necessary for targeting the specific gene that can cause mutational changes and abnormalities in the normal cells of living organisms [5-6]. Sequencing of bacterial genomes has significantly improved our understanding about the biology of many bacterial pathogens as well as identification of novel antibiotic targets.

Sequencing of bacterial genomes helpful for track the different status of fates of mutations that rise and fall through indication of multiple replicates [7]. Molecular technology has been used for extracting the information of specific genes on the basis of primers deigned for targeted sequence. Through this technology, different microbial starins have been isolated and characterized such as T. whipplei, Ehrlichia chaffeensis. On the basis of specific sequences, it is easy to detect changes in the structure of living organisms caused by bacteria. Development of next-generation sequencing, based on pyrosequencing has also made controlling the infectious diseases [8-10].
Specifically, the drugs prevent the bacteria from synthesizing a molecule in the cell wall called peptidoglycan.

Bacterial illness can cause the serious complications due to colonization in the particular host cell. Due to high growth rate, they are potentially cause respiratory tract diseases as a result of insufficient digestions. It indicated the proliferation of a harmful strain of bacteria on or inside the body. However, different methods and techniques have been used for diagnosis and testing of bacterial samples in order to control the arte of infectious diseases. These are sterilization techniques but there is need to existence study at cellular and molecular level for targeting pneumonia, TB, and diarrhea. As the bacteria mutate by passing through different conditions, more resistant to existing antibiotics, making infections harder to treat [11-12].

Antimicrobial resistance have been challenging in the fields of biomedical sciences for misuse of antibiotics due to diverse population of the microbial species which can affected the biological process occurring in the living organisms. Increase in the attack of microbial strains can destroy the natural environment of the normal cells and leads to cellular toxicity to more abundance of microbial species which can increase the use of antibiotics and other pharmaceuticals [13-14]. One of ideal example is the Penicillins as antibacterial drugs that attack a wide range of bacteria. And their discovery has changed the face of medicine, as these drugs have saved millions of lives.

Antibiotics can be obtained from different sources of microbial but due to resistance developing leading a cause of sophisticated mechanisms that causes the abnormalities in cell protein factories for ribosomal 
subsections. A variety of protection needed use by bacteria from the biologically active molecules obtained in the form of nutrition requirements. There is needed to explore the novel antibiotic biosynthesis genes, and their expression is co-regulated through molecular and experimental studies also extensive cell culturing [15]. Taking antibiotics to try and treat viral illnesses might produce the large variety of chemical compounds in the future. Since, majority of antibiotics can only treat sicknesses caused by bacteria at certain concentrations, through appropriate gene cloning and expressed through bioinformatics tools as valuable for decreasing the resistance caused by different types of microbes.

Pathogenic bacteria that are involved in causing of infectious diseases and considered are master engineers of highly diverse and biologically active molecules [15-17]. Escherichia coli and pathogenic Salmonella species are the most common pathogenic forms that damages to the intestines of both animals and humans through fecal contamination in food and water bodies [18]. The modern world has conditions the of growing bacteria for treatment of various diseases sometimes, unhygienic environment are adopting or acquiring resistant genes by bacteria can cause risk of other infectious diseases such as diabetes, end-stage renal disease, or rheumatoid arthritis [19-22].

Immune system of the body has ability to detect the pathogenic and good such as microbes good" microbiota. These good microbars prompted the digestion in such a way that digestive system ability to secrete out the chemicals and acids in order to prevent the walls of alimentary canal from cancer. While on the other hand, sometimes body is unable to respond the good" microbiota, as a result of this, pathogenic microbes increasing the attack and leads to borne of different diseases. It happens in the human immunodeficiency virus (HIV), when the immune system able to response poorly and in some cases, under medications may can proliferate and cause harm to the host in terms of opportunistic infections [23-24]. Intracellular protozoans of the genus Leishmania are the common agents of leishmaniasis, a group of parasitic diseases endemic concerns. The other forms of microbes are deadly viruses are Ebola that causes fever, body aches, and diarrhea, and sometimes bleeding inside and outside the body. The main target of this virus is the immune system and organs [25-28].

Many of the lethal parasites have become the major cause of infections especially in human. For instance, helminthes is the worm-like parasites that survive by feeding on a living host to gain nourishment and protection, sometimes resulting in illness of the host. It exists all over the world in water and soil [2933]. Higher the concentrations of the polluted water and excess of heavy metals, causing the risk of borne of many parasites that ultimately damaged the organs such as digestive system. While on the other hand, low concentrations of the polluted water can activate the immune system against foreign pathogens. White blood cells produced antitoxins in response to entry of parasites or other microbial pathogens, which destroy the toxins, invaded the body. Tetanus, diphtheria and scarlet fever are all diseases where the bacteria secrete toxins $[34,35]$.

\section{CONCLUSION}

Due to increasing the number of infectious diseases from different microprobes, resistance to specific chemicals compounds pharmaceuticals rapidly growing environment. Gene modifications, cloning and expression of targeting microprobes can control the severity of infectious diseases. Genetic engineering based biomedical therapies needed to understand the target microbial cell, protein factory that secreted the variety of products. It will leads to the development of engineered microbes to cure certain human diseases. Antibiotic resistance and target genes of pathogens can be main route in biomedical therapies. It will helpful to control the infections rate.

\section{REFERENCES}

1. Cowell, A. N., \& Winzeler, E. A. (2019). Advances in omics-based methods to identify novel targets for malaria and other parasitic protozoan infections. Genome medicine, 11(1), 1-17.

2. Smith, H. (1991). The Leeuwenhoek Lecture, 1991. The influence of the host on microbes that cause disease. Proceedings of the Royal Society of London. Series B: Biological Sciences, 246(1316), 97-105.

3. Blaser, M. J. (2006). Who are we? Indigenous microbes and the ecology of human diseases. EMBO reports, 7(10), 956-960.

4. Wilson, J. W., M. J. Schurr, C. L. LeBlanc, R. Ramamurthy, K. L. Buchanan, and Cheryl A. Nickerson. "Mechanisms of bacterial pathogenicity." Postgraduate medical journal 78, no. 918 (2002): 216-224.

5. Daffe, M., and G. Etienne. "The capsule of Mycobacterium tuberculosis and its implications for pathogenicity." Tubercle and lung disease 79, no. 3 (1999): 153-169.

6. Pennisi, Elizabeth. "The man who bottled evolution." (2013): 790-793.

7. Weisburg, William G., Susan M. Barns, Dale A. Pelletier, and David J. Lane. "16S ribosomal DNA amplification for phylogenetic study." Journal of bacteriology 173, no. 2 (1991): 697-703.

8. Relman, David A., Thomas M. Schmidt, Richard P. MacDermott, and Stanley Falkow. "Identification of the uncultured bacillus of Whipple's disease." New England Journal of Medicine 327, no. 5 (1992): 293-301.

9. Ronaghi, Mostafa, Mathias Uhlén, and Pål Nyrén. "A sequencing method based on real-time 
Muhammad Tahir et al; Saudi J Pathol Microbiol, Jan, 2022; 7(1): 24-28

pyrophosphate." Science 281, no. 5375 (1998): 363-365.

10. Schnichels, S., Paquet-Durand, F., Löscher, M., Tsai, T., Hurst, J., Joachim, S. C., \& Klettner, A. (2021). Retina in a dish: Cell cultures, retinal explants and animal models for common diseases of the retina. Progress in retinal and eye research, 81,100880 .

11. Hay, S. I., Rao, P. C., Dolecek, C., Day, N. P., Stergachis, A., Lopez, A. D., \& Murray, C. J. (2018). Measuring and mapping the global burden of antimicrobial resistance. BMC medicine, 16(1), 1-3.

12. Soares, R. R. (2007). On the determinants of mortality reductions in the developing world. Population and Development Review, 33(2), 247-287.

13. Sonnenburg, J. L., \& Sonnenburg, E. D. (2019). Vulnerability of the industrialized microbiota. Science, 366(6464).

14. Mak, S., Xu, Y., \& Nodwell, J. R. (2014). The expression of antibiotic resistance genes in antibiotic-producing bacteria. Molecular microbiology, 93(3), 391-402.

15. Challinor, V. L., \& Bode, H. B. (2015). Bioactive natural products from novel microbial sources. Annals of the New York Academy of Sciences, 1354(1), 82-97.

16. Newstead, L. L., Varjonen, K., Nuttall, T., \& Paterson, G. K. (2020). Staphylococcal-produced bacteriocins and antimicrobial peptides: Their potential as alternative treatments for Staphylococcus aureus infections. Antibiotics, 9(2), 40.

17. Mpundu, P., Mbewe, A. R., Muma, J. B., Zgambo, J., \& Munyeme, M. (2019). Evaluation of bacterial contamination in dressed chickens in Lusaka Abattoirs. Frontiers in public health, 7, 19.

18. Boolchandani, M., D’Souza, A. W., \& Dantas, G. (2019). Sequencing-based methods and resources to study antimicrobial resistance. Nature Reviews Genetics, 20(6), 356-370.

19. Ventola, C. L. (2015). The antibiotic resistance crisis: part 1: causes and threats. Pharmacy and therapeutics, 40(4), 277.

20. WHO: The top 10 causes of death. URL: http:www.who.intmediacentrefactsheetsfs310en

21. Jones, K. E., Patel, N. G., Levy, M. A., Storeygard, A., Balk, D., Gittleman, J. L., \& Daszak, P. (2008). Global trends in emerging infectious diseases. Nature, 451(7181), 990-993.

22. Ryan, K. J., \& Ray, C. G. (2004). Medical microbiology. McGraw Hill, 4, 370.

23. Sudheer, S., Gangwar, P., Usmani, Z., Sharma, M., Sharma, V. K., Sana, S. S., ... \& Nabavi, S. M. (2021). Shaping the gut microbiota by bioactive phytochemicals: An emerging approach for the prevention and treatment of human diseases. Biochimie.

24. van Baalen, M., \& Sabelis, M. W. (1995). The dynamics of multiple infection and the evolution of virulence. The American Naturalist, 146(6), 881910.

25. Turelli, M. (1994). Evolution of incompatibilityinducing microbes and their hosts. Evolution, 48(5), 1500-1513.

26. Holden, N., Kredics, L., \& Barak, J. (2020). Thematic issue on Human Pathogens in the Environment: biology and risk factors. FEMS microbiology letters, 367(8), fnaa068.

27. Tariq, S., Wani, S., Rasool, W., Shafi, K., Bhat, M. A., Prabhakar, A., ... \& Rather, M. A. (2019). A comprehensive review of the antibacterial, antifungal and antiviral potential of essential oils and their chemical constituents against drugresistant microbial pathogens. Microbial pathogenesis, 134, 103580.

28. Tariq, S., Wani, S., Rasool, W., Shafi, K., Bhat, M. A., Prabhakar, A., ... \& Rather, M. A. (2019). A comprehensive review of the antibacterial, antifungal and antiviral potential of essential oils and their chemical constituents against drugresistant microbial pathogens. Microbial pathogenesis, 134, 103580.

29. Opal, S. M., Wherry, J. C., \& Grint, P. (1998). Interleukin-10: potential benefits and possible risks in clinical infectious diseases. Clinical infectious diseases, 27(6), 1497-1507.

30. Suk, J. E., Van Cangh, T., Beaute, J., Bartels, C., Tsolova, S., Pharris, A., ... \& Semenza, J. C. (2014). The interconnected and cross-border nature of risks posed by infectious diseases. Global health action, 7(1), 25287.

31. King, D. A., Peckham, C., Waage, J. K., Brownlie, J., \& Woolhouse, M. E. (2006). Infectious diseases: preparing for the future. Science, 313(5792), 1392 1393.

32. Espinosa, R., Tago, D., \& Treich, N. (2020). Infectious diseases and meat production. Environmental and Resource Economics, 76(4), 1019-1044.

33. Knight, J. (2007). Polymorphisms in tumor necrosis factor and other cytokines as risks for infectious diseases and the septic syndrome. Current infectious disease reports, 3(5), 427-439.

34. Goldstein, E., Pitzer, V. E., O'Hagan, J. J., \& Lipsitch, M. (2017). Temporally varying relative risks for infectious diseases: implications for infectious disease control. Epidemiology (Cambridge, Mass.), 28(1), 136.

35. Lindahl, J. F., \& Grace, D. (2015). The consequences of human actions on risks for infectious diseases: a review. Infection ecology \& epidemiology, 5(1), 3004. 